Proceedings

\title{
Alluvial Water Source Capacity under the Climate Change and Other Impacts - Case Study of the Pek River in Serbia ${ }^{+}$
}

\author{
Dejan Dimkić *, Stevan Prohaska, Bojan Stanković and Predrag Pajić \\ Jaroslav Černi Institute for the Development of Water Resources, 11226 Belgrade, Serbia; \\ stevan.prohaska@jcerni.co.rs (S.P.); bojan.stankovic@jcerni.co.rs (B.S.); predragpajic@yahoo.com (P.P.) \\ * Correspondence: dejan.dimkic@jcerni.co.rs; Tel.: +381-62-8013380 \\ + Presented at the 3rd EWaS International Conference on "Insights on the Water-Energy-Food Nexus", \\ Lefkada Island, Greece, 27-30 June 2018.
}

Published: 14 September 2018

\begin{abstract}
River discharge changes, in addition to natural variability, depend on several factors. Three factors are the most important: climate change (CC), changes in human use of water (HU), and land use changes (LU). River discharge has hydraulic connection with its alluvial sources and both are sensitive to climate and other changes. Alluvial water sources (ALWSs) are often used for water supplying purposes. The question is what could we expect in the future? Are they more or less sensible on climate change and other two factors, compare to river discharge changes, or it differ from case to case?
\end{abstract}

Keywords: CC Waters; Pek river; climate change; water demand; river discharge; temperature; precipitation

\section{Introduction and Present State}

Changes in river discharge regimes has been registered in Serbia, as well as in many other parts of the world [1]. Within the scope of the international project "CC Waters" [2], one of the pilot areas, which is addressed in this paper, is the catchment area (C.A.) of the Pek river and two of its alluvial water sources: Jelak (providing drinking water supply for the City of Veliko Gradište) and Mlaka (servicing the City of Kučevo). These two ALWSs were selected because they face similar water quantity issues regarding river discharge, but with possibly different impacts on the water sources. All three factors were considered (CC, HU, LU). Paper describe methodology and discuss obtained results.

The Pek River is situated in central-eastern Serbia. The geographic locations of the cities, temperatures $(\mathrm{T})$ and precipitation $(\mathrm{P})$ stations in the Pek River C.A. are shown in Figure 1.

The altitudinal range is from 72 to $1066 \mathrm{~m}$ above sea level. The Pek River is a tributary of the Danube, and their confluence is at the City of Veliko Gradište (V. Gradište). The surface area of the Pek River C.A. is $1230 \mathrm{~km}^{2}$, with a population of approximately 45,000 . The majority of the population lives in three cities: Majdanpek (the most upstream city), Kučevo, and V. Gradište at the mouth of the river. Population growth has been recorded only in V. Gradište, while the other cities and particularly villages report a decline.

The mean annual temperature and precipitation are about $11.1^{\circ} \mathrm{C}$ and $643 \mathrm{~mm} / \mathrm{y}$ at V. Gradište, and $10.9{ }^{\circ} \mathrm{C}$ and $672 \mathrm{~mm} / \mathrm{y}$ at Kučevo. The approximate average rates of abstraction for urban drinking water supply are: Majdanpek 70 L/s, Kučevo 25 L/s, and V. Gradište 40 L/s. 


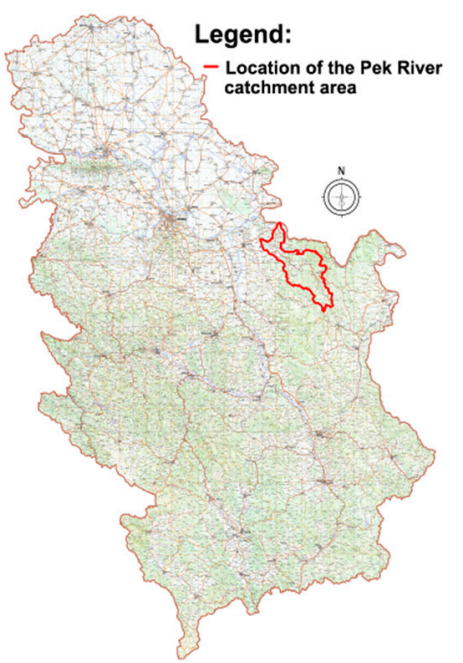

(a)

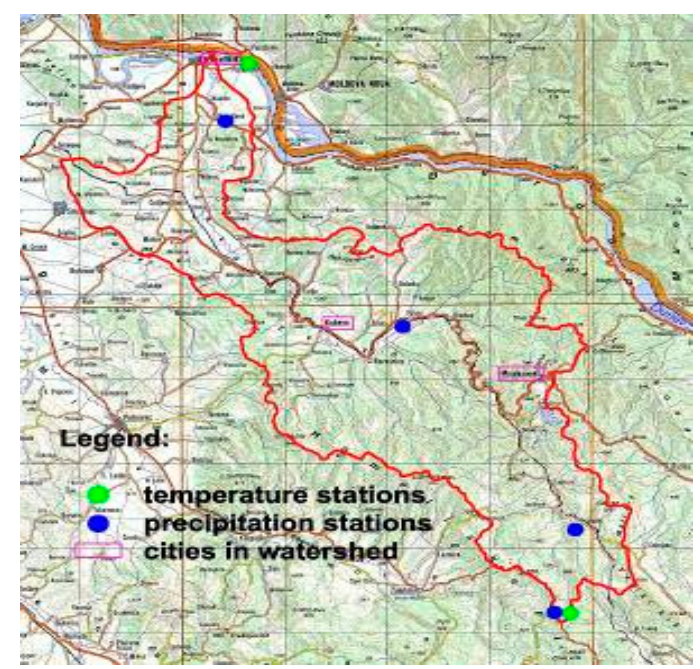

(b)

Figure 1. Location of the Pek River C.A. (a), positions of the cities, T and P stations in the C.A. (b).

During the summer, drinking water demand increases significantly in V. Gradište (the only tourist destination in the area, albeit not major), but not as much in Kučevo. There is no treatment except for chlorination. Agriculture near the cities has remained at about the same level for many years, while it has declined in the villages. In recent years, the water supply system (WSS) of V. Gradište has been experiencing water shortages during the hot months of hydrologically dry or even average years. The Kučevo WSS does not currently face drinking water deficit issues, but they are likely to occur in the future.

Table 1 shows recorded temperature, precipitation and discharge trends at several stations in the Pek C.A. for the 1949-2006 period. This period is convenient because it is relatively long (58 years) and exhibits a close similarity to estimated long-term temperature and precipitation trends, and particularly discharge trends in Serbia [3,4].

Table 1. Registered 1949-2006 trends by month and annual averages.

\begin{tabular}{|c|c|c|c|c|c|c|c|c|c|c|c|c|c|c|}
\hline $\begin{array}{l}\text { Type of } \\
\text { Station }\end{array}$ & Station & Jan & Feb & Mar & Apr & May & Jun & Jul & Aug & Sep & Oct & Nov & Dec & Aver \\
\hline $\mathrm{T}\left({ }^{\circ} \mathrm{C} / 100 \mathrm{y}\right)$ & Veliko Gradište & 1.3 & 1.0 & 2.2 & -0.7 & 1.1 & 0.5 & 0.6 & 0.5 & -2.1 & 0.0 & -1.8 & -2.9 & $0.0^{1}$ \\
\hline $\mathrm{P}(\% / 100 \mathrm{y})$ & $\begin{array}{c}\text { Braničevo (near } \\
\text { VG) }\end{array}$ & -50.3 & -39.4 & -47.0 & 76.1 & -106.7 & -23.0 & 4.3 & 63.0 & 98.6 & 36.2 & -78.2 & -39.8 & $-10.5^{2}$ \\
\hline $\mathrm{P}(\% / 100 \mathrm{y})$ & $\begin{array}{l}\text { Voluja (near } \\
\text { KU) }\end{array}$ & -22.9 & -70.1 & 9.2 & 58.2 & -54.8 & -76.7 & -76.6 & 21.8 & 7.0 & 13.1 & -93.0 & -45.5 & $-31.0^{2}$ \\
\hline $\mathrm{P}(\% / 100 \mathrm{y})$ & $\begin{array}{l}\text { Vlaole (near } \\
\text { MA) }\end{array}$ & -66.3 & -54.0 & -49.7 & 1.0 & -76.0 & -24.8 & -30.9 & 56.6 & 64.5 & -50.9 & -96.4 & -43.1 & $-33.6^{2}$ \\
\hline $\mathrm{Q}(\% / 100 \mathrm{y})$ & $\begin{array}{l}\text { Kusići (V. } \\
\text { Gradište) }\end{array}$ & -35.2 & -38.6 & -10.9 & -19.3 & -71.8 & -123.6 & -50.6 & -4.5 & 9.6 & 3.5 & -122 & -64.6 & $-43.5^{3}$ \\
\hline
\end{tabular}

${ }^{1}$ The estimated present average annual $\mathrm{T}$ trend for this region is about $+0.5{ }^{\circ} \mathrm{C} / 100$ years [3-6]. ${ }^{2}$ The estimated present average annual $P$ trend for this region is about $-10 \% / 100$ years [3-6]. ${ }^{3}$ Very close to the present average annual $Q$ trend for the region in which the Pek C.A. is located [3-5].

The months of August and September, followed by July and October, are of particular interest when the impact of climate change on water resources is assessed because they exhibit the most critical relationship between the availability of water resources and water demand. The low flow trend in August, September and October is about " 0 " - there is no trend, and this is considerably more favorable than the annual average as a result of an upward precipitation trend in August and September, and in the case of the Pek C.A., also due to the presence of the Pustinjac Reservoir which provides drinking water supply to the most upstream city-Majdanpek.

There are three hydrological stations on the Pek River: an upstream station at Debeli Lug (near Majdanpek), a central station at Kučevo, and a downstream station at Kusiće (near V. Gradište). Figure 
2 shows their observed annual discharge and trends. The longest existing time series for these stations have been included and a national study indicate that the registered long-term trend for the Pek River is about $-40 \% / 100$ years. The greatest factor are attributed to CC, after that to LU [4].

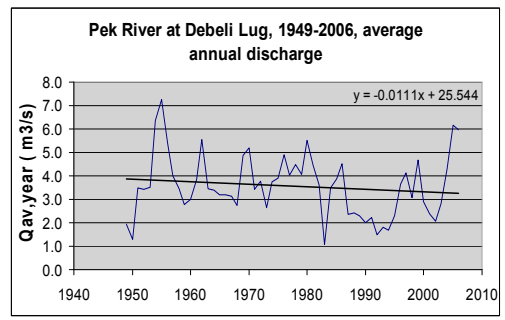

Trend $=-0.0111 \times 10000 / 3.561=-31.2 \% / 100 \mathrm{y}$.

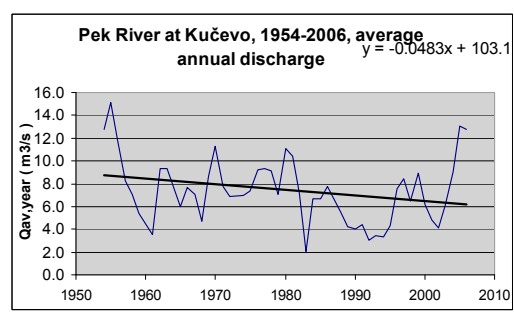

Trend $=-0.0483 \times 10000 / 7.414=-65.2 \% / 100 \mathrm{y}$.

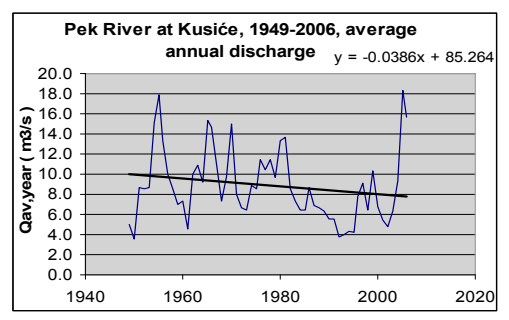

Trend $=-0.0386 \times 10000 / 8.877=-43.5 \% / 100 \mathrm{y}$.

Figure 2. Observed annual trends at the three hydrological stations on the Pek River.

\section{Methodology}

Figure 3 shows the general methodology (GM, or needed steps) followed to assess climate change impacts on ALWSs in the Pek Test Area. Each step has been assigned a number and is addressed later in the text. Simplifications and assumptions:

- Each ALWS can be upgraded (new wells, artificial recharge, and the like). Additionally, all wells exhibit signs of declining discharge, to a greater or lesser extent, due to clogging. Such possibilities and processes are not taken into account in the assessment of climate change impacts on the ALWSs (i.e., the ALWSs are modeled as being the same today and in the future). The ALWS setting is the same today and in the future (no erosion, no siltation, and no morphological changes in the immediate environment). The assessment does not examine whether the capacity of a particular ALWS is adequate or not for the area it services.

- The groundwater (GW) model calibration time step is one week (GM, Steps 1 and 2), September-December 2010 (Jelak-V. Gradište) and March-June 1997 (Mlaka-Kučevo), while the calculation time step is one month, consistent with available data (GM, Step 9).

- Climate forecast parameters (T and P) were obtained from other CC Waters project partners (GM, Step 3). The climatic scenario used was A1B.

- Land use within the C.A. will not change significantly in the future and, as such, will not result in any runoff coefficient or water balance variation in the upstream portion of the C.A. (GM, Step 4).

- The water balance was not assessed using the conventional hydrologic method. Instead, the multiple non-linear correlation method (VNC) was used, as the dependency of discharge on temperature and precipitation, with corrections for additional water demand and possibly additional evapotranspiration. Changes in the rates of water abstraction for future irrigation and drinking water supply needs upstream from a given river discharge are taken into account, under optimistic (minimum), moderate (plausible) and pessimistic (maximum) scenarios. The additional evapotranspiration was also looked into under three scenarios (optimistic, moderate and pessimistic). Following discharge calculations, the river boundary condition for the HD model was determined based on the established correlation between river discharge and water level, via a large number of recorded data points: discharge-water level pairs (GM, Step 5).

- The time periods considered were: 1961-1990 (base period), and 2021-2050 and 2071-2100 (future periods). Based on recorded hydrologic data and estimated future climatic and hydrologic data, selected critical years are: V. Gradište-1962 (past), and 2035 and 2096 (future); and Kučevo-1961 (past), and 2035 and 2096 (future). Critical months were always July through October, such that the HD models were run through the March-October period (GM, Step 6).

- For the calibration period, GW flow from the upland was found to be about $30 \mathrm{~L} / \mathrm{s} / \mathrm{km}$ (Jelak-VG) and $18 \mathrm{~L} / \mathrm{s} / \mathrm{km}$ (Mlaka-KU). For estimated periods, groundwater flow from the upland was determined based on experience, taking into account that the downward trend of 
groundwater flow from the upland is about the same or slightly lower than the downward trend obtained for the Pek River, all other conditions being equal (GM, Step 7).

- Two values were assumed for the achievement of a given water level at the wells, as a criterion (GM, Step 8) which is the same for all time periods and scenarios, based on which HD model calculations were performed. The first is slightly above the aquifer floor (the average of 5 wells $\approx 68.2$ m.a.s.l. at the V. Gradište ALWS, and the average of 3 wells $\approx 149.5$ m.a.s.l. at the Kučevo ALWS), corresponding to the maximum yield of the source under given conditions, while the second is about $0.5 \mathrm{~m}$ higher (the average $\approx 68.7 \mathrm{~m}$.a.s.l. at the VG ALWS and the average $\approx 150.0$ m.a.s.l. at KU ALWS), corresponding to the lower yield of each of the sources.

- The following will change in the future, relative to the present: temperature and precipitation; upstream water demand for drinking water supply and irrigation; and, as a consequence of climate change, evapotranspiration and river and upland boundary conditions.

- There are no special ecosystems; ecological criteria apply to the downstream consumer (at Kučevo) and to biodiversity of the river itself.

Calculations were done for:

- Modflow software were used to develop HD models of the ALWSs, like in similar cases [7,8],

- Ecological water demand have been estimated base on the nature condition,

- The Pek River water levels at the ALWSs, based on water balance model and estimation of future water demand,

- Upland boundary conditions and recharge for both ALWSs have been estimated base on observations and predicted future conditions.

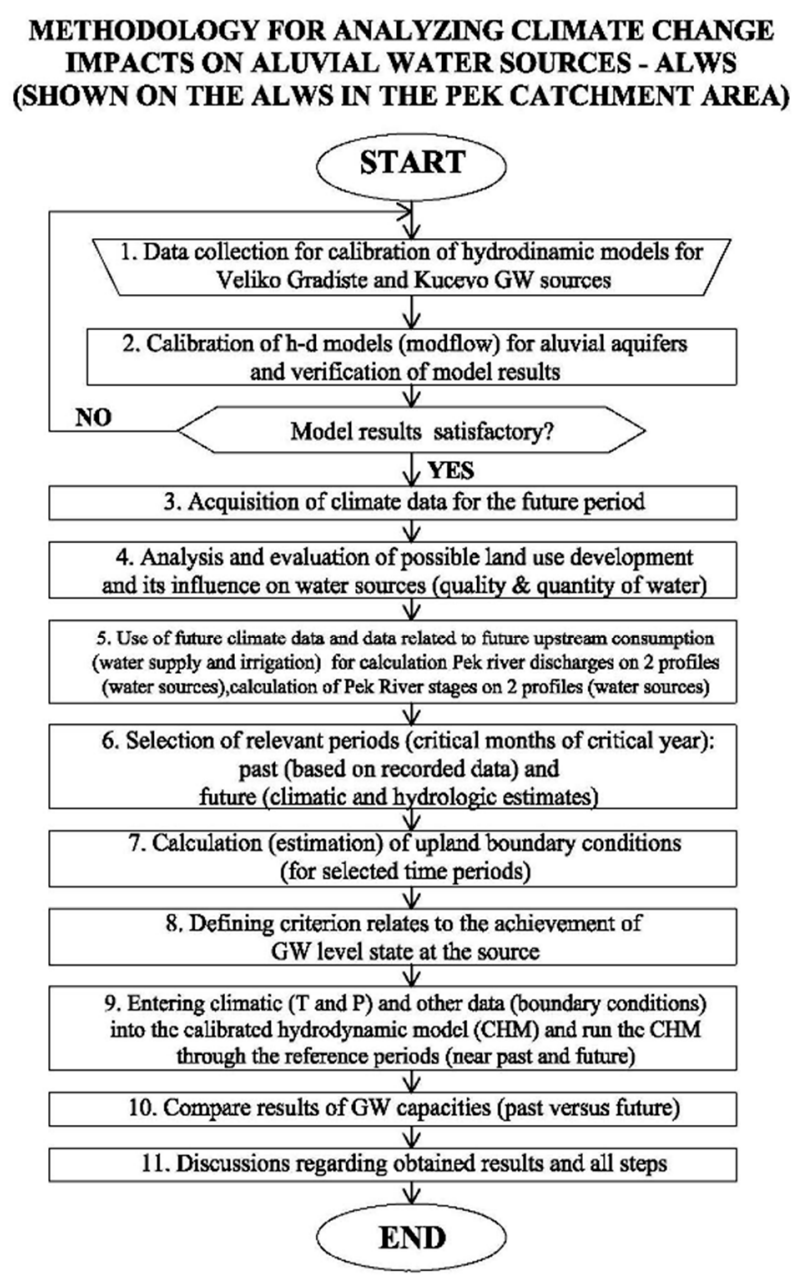

Figure 3. General methodology. 


\section{Results Derived for ALWS Capacities}

Tables 2-5 show, separately, the values derived for the entire year (Tables 2 and 4), and for the summer and winter periods (Tables 3 and 5) for both ALWS-GM, Step 10.

Tables 2 (Jelak-VG) and 4 (Mlaka-KU) shows ALWS annual average capacities for the periods addressed (1961-1990, 2021-2050, 2071-2100). Minimum (maximum) values are given for one year (out of 30 years), in which the ALWS exhibits the lowest (highest) average annual capacity.

Tables 3 (Jelak-VG) and 5 (Mlaka-KU) shows ALWS capacities on a monthly basis during the most critical (lowest) year in the periods addressed (1961-1990, 2021-2050, 2071-2100). Minimum (maximum) values represent the month during the selected year in which the ALWS exhibits the lowest (highest) monthly average capacity. The plausible (average) values in these tables are the same as the minimum values in Tables 2 and 4, respectively.

Table 2. Water Availability based on average annual hydrology at Jelak-VG.

\begin{tabular}{ccccccccccc}
\hline Veliko Gradiste & \multicolumn{3}{c}{ Average } & \multicolumn{4}{c}{ Average for Apr.-Sept. } & \multicolumn{3}{c}{ Average for Oct.-March } \\
\hline Period & Min. & Plausible & Max. & Min. & Plausible & Max. & Min. & Plausible & Max. \\
\hline $1961-1990(\mathrm{~L} / \mathrm{s})$ & 56 & 62 & 65 & 55 & 60 & 63 & 58 & 64 & 66 \\
$2021-2050(\mathrm{~L} / \mathrm{s})$ & 49 & 55 & 60 & 48 & 54 & 58 & 50 & 57 & 63 \\
$2071-2100(\mathrm{~L} / \mathrm{s})$ & 39 & 44 & 49 & 38 & 43 & 47 & 41 & 46 & 52 \\
$(2021-50) /(1961-90)$ & 0.88 & 0.89 & 0.92 & 0.88 & 0.90 & 0.92 & 0.88 & 0.89 & 0.95 \\
$(2071-2100) /(61-90)$ & 0.70 & 0.71 & 0.75 & 0.70 & 0.72 & 0.75 & 0.71 & 0.72 & 0.79 \\
\hline
\end{tabular}

Table 3. Water availability based on average monthly hydrology-worst year of the period, at Jelak.

\begin{tabular}{|c|c|c|c|c|c|c|c|c|c|}
\hline \multirow{2}{*}{$\begin{array}{c}\text { Veliko Gradiste } \\
\text { Period }\end{array}$} & \multicolumn{3}{|c|}{ Average } & \multicolumn{3}{|c|}{ Average for Apr.-Sept. } & \multicolumn{3}{|c|}{ Average for Oct.-March } \\
\hline & Min. & Plausible & Max. & Min. & Plausible & Max. & Min. & Plausible & Max. \\
\hline $1962(\mathrm{~L} / \mathrm{s})$ & 52 & 56 & 61 & 52 & 55 & 59 & 52 & 58 & 61 \\
\hline $2035(\mathrm{~L} / \mathrm{s})$ & 44 & 49 & 54 & 44 & 48 & 53 & 47 & 50 & 54 \\
\hline 2096 (L/s) & 36 & 39 & 44 & 36 & 38 & 43 & 38 & 41 & 44 \\
\hline $2035 / 1962$ & 0.86 & 0.88 & 0.89 & 0.86 & 0.88 & 0.89 & 0.90 & 0.88 & 0.89 \\
\hline 2096/1962 & 0.69 & 0.70 & 0.72 & 0.69 & 0.70 & 0.72 & 0.72 & 0.71 & 0.72 \\
\hline
\end{tabular}

Table 4. Water Availability based on average annual hydrology at Mlaka-KU.

\begin{tabular}{cccccccccc}
\hline Kucevo & \multicolumn{3}{c}{ Average } & \multicolumn{4}{c}{ Average of Apr.-Sept. } & \multicolumn{3}{c}{ Average of Oct.-March } \\
\hline Period & Min. & Plausible & Max. & Min. & Plausible & Max. & Min. & Plausible & Max. \\
\hline $1961-1990(\mathrm{~L} / \mathrm{s})$ & 28 & 32 & 35 & 26 & 30 & 33 & 30 & 34 & 36 \\
$2021-2050(\mathrm{~L} / \mathrm{s})$ & 25 & 28 & 31 & 22 & 25 & 28 & 28 & 31 & 33 \\
$2071-2100(\mathrm{~L} / \mathrm{s})$ & 18 & 20 & 22 & 15 & 17 & 19 & 21 & 24 & 26 \\
$(2021-50) /(1961-90)$ & 0.89 & 0.88 & 0.89 & 0.85 & 0.83 & 0.85 & 0.93 & 0.91 & 0.92 \\
$(2071-2100) /(61-90)$ & 0.64 & 0.63 & 0.63 & 0.57 & 0.57 & 0.58 & 0.70 & 0.71 & 0.72 \\
\hline
\end{tabular}

Table 5. Water availability based on average monthly hydrology-worst year of the period, at Mlaka.

\begin{tabular}{cccccccccc}
\hline Kucevo & \multicolumn{3}{c}{ Average } & \multicolumn{4}{c}{ Average of Apr.-Sept. } & \multicolumn{3}{c}{ Average of Oct.-March } \\
\hline Period & Min. & Plausible & Max. & Min. & Plausible & Max. & Min. & Plausible & Max. \\
\hline 1961 (L/s) & 24 & 28 & 33 & 24 & 26 & 29 & 25 & 30 & 33 \\
2035 (L/s) & 21 & 25 & 31 & 21 & 22 & 24 & 23 & 28 & 31 \\
2096 (L/s) & 14 & 18 & 23 & 14 & 15 & 16 & 18 & 21 & 23 \\
$2035 / 1961$ & 0.89 & 0.89 & 0.94 & 0.89 & 0.85 & 0.83 & 0.91 & 0.93 & 0.94 \\
$2096 / 1961$ & 0.57 & 0.64 & 0.70 & 0.57 & 0.57 & 0.56 & 0.72 & 0.70 & 0.70 \\
\hline
\end{tabular}


Results indicate that, for the near future, it could be expected that capacities decline about $10-15 \%$ on both alluvial water sources, while this percentage is higher for the distant future: about $30 \%$ for Jelak and about $45 \%$ for Mlaka alluvial water source.

When the results derived for the two ALWSs are compared, it is apparent that Mlaka (Kučevo) is more sensitive than Jelak (V. Gradište) to climate change (primarily evident from the correlation between the 2096 capacity and that of the years which are representative of the present state). The explanation of this may be sought in the lower permeability of Mlaka, as well as the proximity of the Danube River to Jelak.

\section{Discussions Regarding Uncertainties and Obtained Results}

The Climate Change and Impacts on Water Supply in SE Europe Program involves, by necessity, a large number of assumptions and calculations. Each forecast is sensitive to assumption uncertainties and calculation imperfections. They need to be examined and critically assessed. The quality of a prediction grows with increasing validation by recorded data and especially by trends. Following is a commentary on the main work activities conducted under the Program.

\subsection{Climate Predictions}

Temperature and precipitation calibrations for the Pek C.A. are deemed to be very good. Since only one scenario, the "middle" scenario A1B, was selected, it is safe to conclude that the climate forecast targeted the most realistic climate developments. For the Pek Test Area, the adopted climate model CNRM-RM5 predicts an increase in the average annual temperature by $3.1^{\circ} \mathrm{C} / 100$ years. The current temperature trend of the region which includes the Pek C.A. is about $0.5^{\circ} \mathrm{C} / 100$ years (the observed average for Serbia is app. double higher).

This upward average annual trend is likely a result of the assumption inherent in the climate scenario, but the distribution of monthly trends is questionable: the highest upward trend was predicted for the months of July, August and September (in the order of 6,5 and $4.5^{\circ} \mathrm{C} / 100$ years), and is considerably higher than the predicted annual trend, while the actual trends for July and August in the Pek C.A. (and in all of Serbia as well) are only slightly higher than the annual average, and September, along with November and December, is the only month with a distinct negative temperature trend (in the order of $-1.5{ }^{\circ} \mathrm{C} / 100$ years).

The precipitation situation is similar (Figure 4): For the Pek C.A., the selected model CNRM-RM5 predicts a reduction in precipitation by $-9 \% / 100$ years, which matches very well the current precipitation trend in the region which includes the Pek C.A. Again the distribution of monthly trends is questionable: the highest downward trend was predicted for the months of July, August and September (in the order of $-55,-45$ and $-25 \% / 100$ years), which is inferior to the predicted annual trend, while the actual trends in July, August and September in the region which includes the Pek C.A. are in the order of $-20,+40$ and $+50 \% / 100$ years. September is at the same time the month with the highest and most constant positive precipitation trend in all of Serbia.

From the standpoint of critical periods for drinking water supply (July-October), the predicted climate parameters, assuming that the A1B scenario was properly selected, provide appreciably more severe (less favorable) values than those that can be deduced from analyses of the trends recorded during this part of the year. 

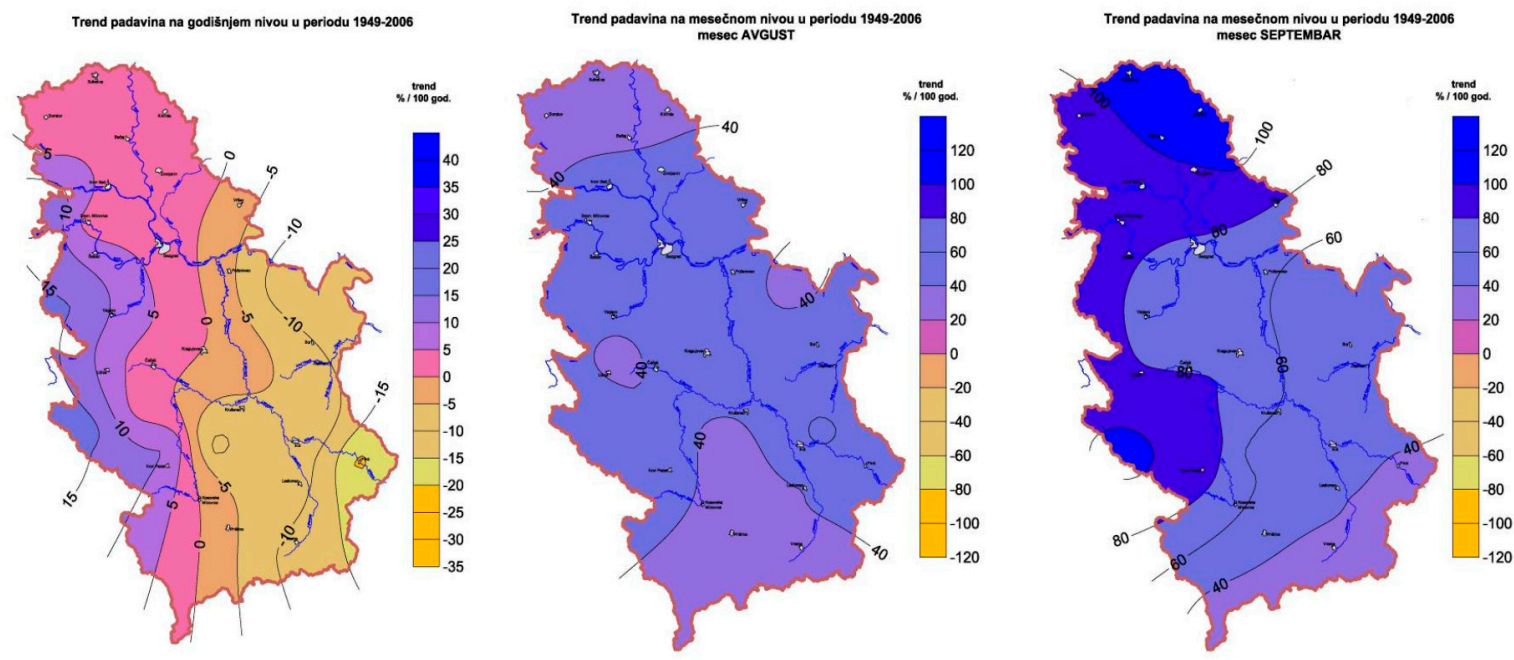

Figure 4. App. long-term annual and monthly for August and September precipitation trends (\%/100 yrs) in Serbia [3-6].

\subsection{Land Use Predictions}

As stated in 2. Methodology, the assumption was that land use within the watershed will not change significantly in the future. There is some uncertainty in this assumption but since no significant trends have been recorded (other than a slight shrinkage of arable land), it seems to be the only plausible assumption. Different rates of water abstraction for irrigation were considered (next bullet).

\subsection{River Hydrology and Water Balance Predictions}

The change in water use for irrigation and water supply was examined under three options: optimistic (minimum), moderate (plausible) and pessimistic (maximum). Although broad-based, they do not have a major impact on hydrologic trends and the water balance (max. shift of the hydrologic trend of the Pek is from some $-20 \% / 100$ years to about $-25 \% / 100$ years).

The water balance was not assessed using the conventional hydrologic method. Instead, the multiple non-linear correlation method (VNC) was used, as the dependency of discharge on temperature and precipitation, with corrections for additional water demand and possibly additional evapotranspiration. There is the question of accuracy of the VNC model, with regard to both the predicted average annual trend (only $-20 \% 100$ years, while the current recorded trend of the Pek is at least double), and, even more so, the intra-annual distribution of discharges and low flows. However, following corrections, the results reflect a (possibly toned down) future state which does not differ too much from recorded values and trends (Figure 2).

The predicted average annual hydrologic parameters exhibit significantly more favorable trends than those that can be deduced from analyses of recorded trends and, with regard to the critical period for drinking water supply (July to October), these parameters exhibit approximately the same or slightly more severe values.

\subsection{Groundwater Flow Predictions, Inciuding Boundary Conditions}

The calibration of both hydrodynamic models appears to be quite good. Calibration results at select piezometers for Mlaka alluvial water source are shown on Figure 5.

A higher calculation accuracy could be sought in the specification of upland boundary conditions (due to the sensitivity of water source capacity results to this boundary condition), provided that a much larger database exists than was available. 

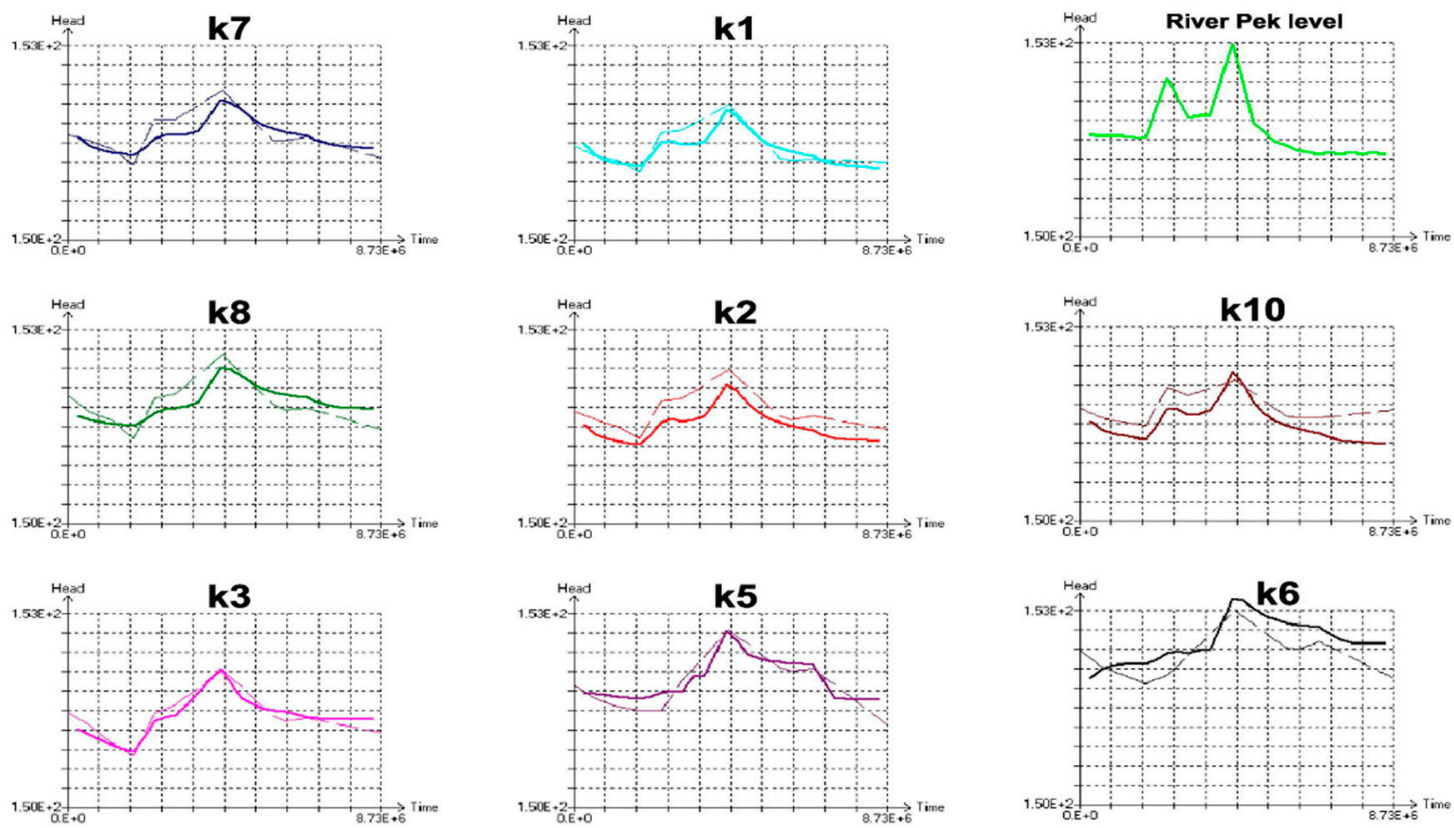

Legend:

- Measured groundwater levels

full line Computed groundwater levels

Figure 5. Model calibration results-parallel representation of measured and computed groundwater levels at select piezometers under transient conditions for the March-June 1997 period. Note: The ordinate shows the piezometric head in meters above sea level, and the abscissa shows the simulation time in seconds (in exponential notation).

\subsection{General Conclusions}

As known, there are a lot of uncertainties always when talking about climate and other changes and forecasting their impact to water source availability. Without enough strong support, it seems to us, that greater uncertainties are related to climate predictions than to derived results for ALWSs capacities for one certain climate scenario.

As a last conclusion, it could be said in general and in line with this attitude, that the derived decreasing capacities of the alluvial water sources in the Pek Valley (Tables 2-5 in moderate option) are approximately the same or very slightly higher than those that could have been expected as plausible, based on analyses of all examined parameters and trends.

Acknowledgments: This paper is an outcome of the International project for SE Europe "CCWaters" funded by European IPA funds, and National scientific project "Assessment of Climate Change Impact on Water Resources in Serbia" (TR37005), funded by the Ministry of Education and Science of the Republic of Serbia.

\section{References}

1. Synthesis Report of the IPCC. Available online: www.ipcc.ch (Nov. 2007).

2. Climate Change and Impacts on Water Supply (CC-WaterS)-International Project for SE Europe, 18 Institutions from SE Europe, May 2009-May 2012. Available online: http://www.ccwaters.eu/ index.php?option $=$ com_content\&view $=$ article\&id $=48 \& I t e m i d=54 \& 56 \mathrm{~b} 00064 \mathrm{c} 3 \mathrm{e} 6 \mathrm{beb} 26 \mathrm{da} 3 \mathrm{~b} 96 \mathrm{~d} 1578 \mathrm{~b} 92 \mathrm{a}=\mathrm{c}$ aac98a9a4248cd115a194c70c97a142

3. Dimkić, D. Present and future mean hydrologic trends in Serbia as a function of climate trends. Desalin. Water Treat. J. 2017, 99, 10-17, doi: 10.5004 /dwt.2017.21547.

4. Climate Change Impacts on River Hydrology in Serbia-National Study; Jaroslav Černi Institute for the Development of Water Resources: Belgrade, Serbia, 2010-2012.

5. Dimkić D. New Method for Estimation Mean Hydrological Changes and Question of Reliability in Forecasting Future Hydrological Regimes. Procedia Eng. 2016, 162, 145-152.

6. Smailagić, J. Climate change in Serbia, Monography. In Memory of Milutin Milanković; Publisher: Association of University professors, Belgrade 2009; pp. 109-120, ISBN 978-86-910313-1-2. 
7. Đuric, D.; Lukic, V.; Soro, A. Hydrodynamic Analyses of Novi Sad Petrovaradinska ada Ground Water Source Expanding; Vodoprivreda Magazine: Belgrade, Serbia, 2012; Volume 44, pp. 265-272; no. 4-6/2012, number 258-260, ISSN 0350-0519.

8. Pušic, M.; Lukic, V.; Jevtic, G. Hydrodynamic Model and Potential Possibilities for New Ground Water Sources Opening in Western SREM Region. In Proceedings of the XIII Symposium on Hydrogeology and Engineering Geology, Herceg Novi, Montenegro, June 2002; pp. 413-420

(c) 2018 by the authors. Licensee MDPI, Basel, Switzerland. This article is an open access article distributed under the terms and conditions of the Creative Commons Attribution (CC BY) license (http://creativecommons.org/licenses/by/4.0/). 